\title{
Mechanical properties of biomorphous ceramics
}

\author{
V.S. Kiselov ${ }^{1}$, Yu.S.Borisov ${ }^{2}$, M.Tryus ${ }^{1}$, S.A Vitusevich ${ }^{3}$, S.Pud ${ }^{3}$ and A.E. Belyaev ${ }^{1}$ \\ ${ }^{I}$ V. Lashkaryov Institute of Semiconductor Physics, NAS of Ukraine, 03028 Kyiv, Ukraine \\ ${ }^{2}$ E.O. Paton Electric Welding Institute, NAS of Ukraine, 03028 Kyiv, Ukraine \\ ${ }^{3}$ Peter Grünberg Institute, Forschungszentrum Jülich, 52425 Jülich, Germany \\ Corresponding author e-mail: vit_kiselov@ukr.net
}

\begin{abstract}
Mechanical properties: The Vickers hardness and bending strength of porous biomorphic $\mathrm{SiC}$ (bioSiC) ceramics fabricated from different natural hardwoods were investigated. It has been found that these parameters are highly dependent on the geometrical densities of ceramics, and Vickers hardness values can be well described using the Ryskevitch-type equation. It has been shown that the data of geometrical density bio-SiC ceramics can be used to estimate mechanical parameters such as bending strength. Materials with advanced properties appropriate for surgical applications are being designed. Further ways to improve the mechanical properties of ceramics and ceramic products have been discussed.
\end{abstract}

Keywords: wood precursors, biomorphous SiC, Vickers hardness, bending strength.

Manuscript received 27.08.12; revised version received 25.09.12; accepted for publication 17.10.12; published online 12.12.12.

\section{Introduction}

At the present time, the search for alternative materials to conventional metallic implants (used in a variety of biomedical applications) has become an increasingly important task. Modern implants are fabricated from titanium, cobalt, stainless steel and alloys of tungsten and molybdenum. They are rather expensive and have a number of drawbacks. Investigations are being conducted on porous ceramic materials based on calcium orthophosphates, zirconium, silicon nitride with $\mathrm{SiC}$ whiskers and others for specific medical applications. In this way, porous silicon carbides are emerging as an important class of materials for a variety of biomedical applications, including the development of dental and orthopedic implants [1-5].

The mechanical properties of new materials, including biomorphic ceramics, are very important parameters. Depending on the specific region of their application in the human body, materials for orthopedic implants must have a wide range of elastic modulus values from $0.01 \ldots 2 \mathrm{GPa}$ for cancellers up to $15 \ldots 30 \mathrm{GPa}$ for human cortical bone. At present, a limited amount of data is available concerning the mechanical properties of biomorphous $\mathrm{SiC}$ (bioSiC) ceramics. Typically, properties of porous ceramics depend on the pore fraction and morphology, as well as on the properties of solid phase. Thus, the aim of this work is to study the mechanical parameters of bioSiC ceramics fabricated from different types of natural hardwoods.

\section{Fabrication of bioSiC samples and measurement technique}

Different types of natural hardwoods widespread in Ukraine (Dicotyledonous angiosperms) with diffusive porous patterns were selected. In particular, pear (Pyrus domestica), beech (Fagus sylvatica), alder (Alnus glutinosa), Persian walnut (Juglans regia) and European hornbeam (Carpinus betulus) were investigated. Samples from sapele wood (Entandrophragma cylindricum) and pine softwood (Pinus) were prepared for comparison.

The well-known liquid silicon infiltration (LSI) technique [6-10] was used for fabrication of bioSiC ceramic samples. Preparation of these samples began with pyrolysis of wood precursors to form amorphous carbon matrices. This was followed by infiltration and reaction of the matrices with molten $\mathrm{Si}$ to form $\mathrm{SiC}$. The 
material that results from this process retains the honeycomb-like microstructure of the original wood precursor, which consists of tubular pores.

In this work, special attention was paid to developing the method for fabrication of carbon biotemplates appropriate for hardness measurements. The samples with characteristic sizes of $14 \times 14 \times 200 \mathrm{~mm}$ were prepared from sapwood in the growth direction of the trunk to decrease dispersion of the results due to difference in pore sizes as well as distance between the growth rings. The samples of different woods were subjected to pyrolysis in argon atmosphere at $900{ }^{\circ} \mathrm{C}$, resulting in amorphous carbon pieces. This method allows samples to be obtained with very similar pore structures and growth ring sizes. The pyrolyzed carbon was then sectioned into $8 \times 8 \times 12 \mathrm{~mm}$ pieces. The samples with characteristic sizes of $5 \times 5 \times 45 \mathrm{~mm}$ were prepared for bending strength measurements. Each sample was placed into an individual graphite crucible with $\mathrm{Si}$ powder. Infiltration of the samples with liquid $\mathrm{Si}$ was performed at temperatures within the range $1750 \ldots 1800{ }^{\circ} \mathrm{C}$. The forced impregnation process was applied to achieve a uniform silicon distribution over the whole bulk of a sample [10]. Each sample of a certain type of the wood was infiltrated with different amounts of excess silicon. It is known that the porous structure and mechanical properties of biomorphous ceramics depend on both the characteristic structure of the wood used as a precursor and the ceramic composition (amount of $\mathrm{SiC}, \mathrm{SiC}+\mathrm{Si}$ or $\mathrm{SiC}+\mathrm{C}$ ). The geometric density of the ceramics is determined from the amount of silicon used during the process. The optimum correlation of the mass of silicon and mass of carbon for $100 \%$ transformation into silicon carbide is determined by the chemical formula of $\mathrm{SiC}$ and molecular weights of $\mathrm{C}(12 \mathrm{~g} / \mathrm{mol})$ and $\mathrm{Si}(28 \mathrm{~g} / \mathrm{mol})$. For $100 \%$ transformation efficiency, the weight balance should be equal to $\psi=\mathrm{Si} / \mathrm{C}=2.33$. If we use $\psi<2.33$, the $\mathrm{SiC} / \mathrm{C}$ composite and at $\psi>3.33$ the $\mathrm{SiC} / \mathrm{Si}$ composite was formed, respectively. Thus, a set of samples of biomorphous ceramics with different geometric densities was prepared from each type of wood. The geometric density was determined by measuring the volume and weighing the samples. The Vickers hardness $\left(H_{v}\right)$ measurements were performed under a load of $0.05 \mathrm{kN}$. Due to the inhomogeneity of the materials, different sets of indentations were made in different regions. The samples were polished prior to indentation. The indenter print was measured by an optical microscope. Vickers hardness $H_{v}$ was calculated from the indentation load and the indenter contact area.

\section{Results and discussion}

\subsection{Vickers hardness measurements}

The surface of biomorphous ceramics is very nonuniform and the results of hardness measurements depend on a porous structure in the neighborhood of the indentation print. This should cause sizeable dispersion of the data. It can be seen from Fig. 1a that ceramics fabricated from pine wood demonstrate considerable inhomogeneity of structure. Two well-differentiated regions can be observed: one that is totally dense, corresponding to the annual ring, and the porous region corresponding to the spring wood. Due to the inhomogeneity of the material, a large scattering of indenter print sizes is observed and, as a result, the values of the measured hardness differ 8-9 times. A question obviously arises concerning the applicability of the Vickers method to such non-uniform samples. On the other hand, ceramics fabricated from hardwoods with diffusive porous patterns demonstrate a respectively uniform structure. It can be seen from Figs $1 \mathrm{~b}$ and 1c that the scattering of indenter print sizes as well as the values of the measured hardness is much smaller. Moreover, in this case distinct regularities become apparent in hardness versus density dependences. All this allows us to assume that the Vickers method can be used for the measurement and evaluation of properties of bioceramics made from hardwood.

The results of measurements of ceramic hardness as a function of density are plotted in Figs 2 and 3. It should be noted that hardness of a sample in the perpendicular direction is considerably lower than in the parallel direction of growth.

It is known that mechanical properties of ceramic materials strongly depend on their porous structure. The Gibson and Ashby solid cellular model [11-13] is generally used to analyze the properties of bioceramics made from softwood (more than $70 \%$ porosity and relatively homogeneous distribution of pores), while the Rice model [14] is used for ceramics made from hardwood. Relative loading in this model is described as an exponential function of porosity:

$N=N_{0} \exp (-B P)$,

where $N$ is the strength of the porous material, $N_{0}$ strength of the dense material, $P$ - porosity, and $B-$ constant that depends on the shape of pores [15].

The elasticity modulus dependence is described by the Ryskevitch equation [15]:

$E=E_{0} \exp (-A P)$,

This may be used to estimate the influence of porosity on the hardness of porous ceramics.

Assuming that

$P=1-\rho_{g} / \rho_{s}$,

where $\rho_{g}$ is the density of the porous material and $\rho_{\mathrm{s}}$ is that of the dense material, yields

$H_{v}=H_{v 0} \exp \left[-B\left(1-\rho_{g} / \rho_{s}\right)\right]$,

where $H_{v}$ is the hardness of the porous material and $H_{v 0}$ - hardness of the dense material, and $B=6.3$, as experimentally determined for $\mathrm{SiC}$ [15].

As a rule, biomorphous $\mathrm{SiC} / \mathrm{Si}$ ceramics consist of two components. Then it becomes obvious that such parameters as $H_{v 0}$ and $\rho_{s}$ for specimens of a different nature depend on their individual properties. 


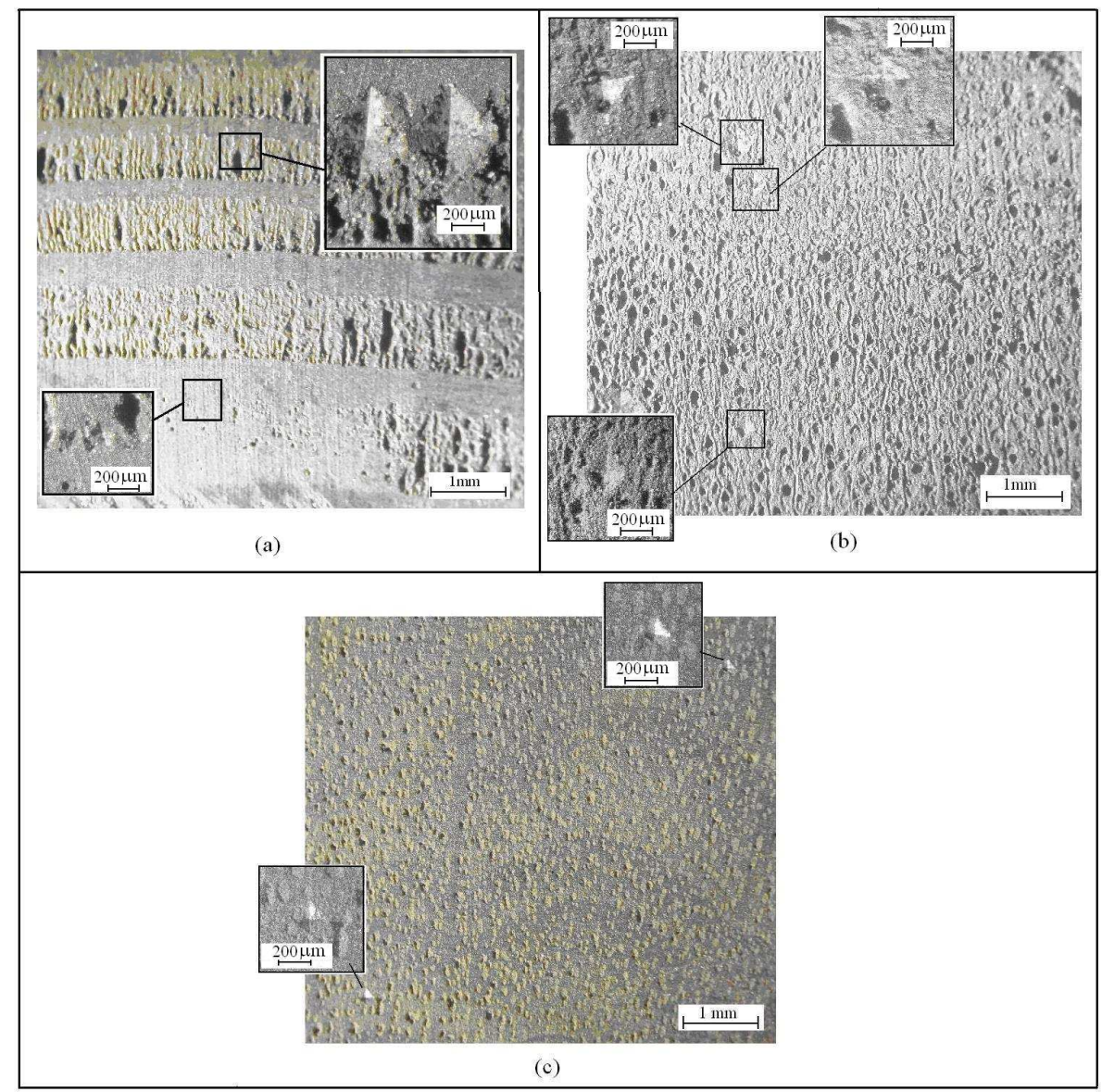

Fig. 1. Optical images of SiC/Si ceramics made from: (a) pine, (b) European hornbeam, and (c) beech. Indenter prints are shown in insets, scale bar is $200 \mu \mathrm{m}$.
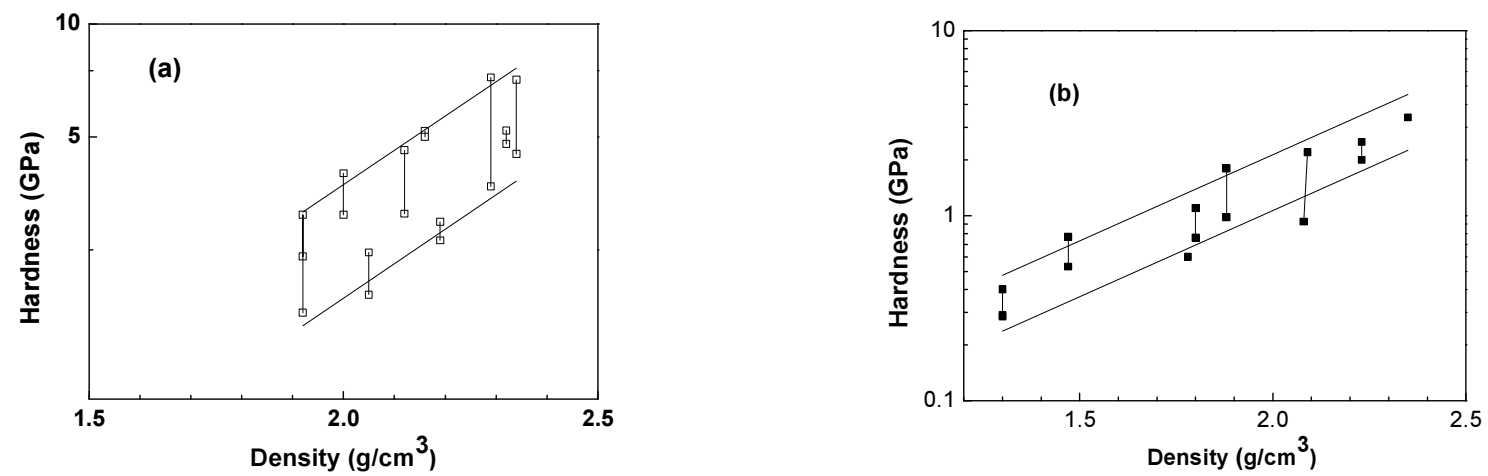

Fig. 2. Hardness results obtained as a function of geometrical density at ambient temperature. Ceramics made from: (a) European hornbeam, (b) sapele wood. Upper lines correspond to orientations parallel to direction of wood growth, lower lines correspond to orientations normal to growth direction.

Let the geometrical density of carbon matrices of a specific sort of wood be $\rho_{\mathrm{C}}$. It is known that under complete transformation into silicon carbide the weight of $\mathrm{SiC}$ in a unit volume is equal to $P_{\mathrm{SiC}}=3.33 \rho_{\mathrm{C}}$, and the volume occupied by $\mathrm{SiC}$ is $V_{\mathrm{SiC}}=3.33 \rho_{\mathrm{C}} / \rho_{\mathrm{SiC}}$. Residual volume $V_{\mathrm{Si}}=1-V_{\mathrm{SiC}}=1-3.33 \rho_{\mathrm{C}} / \rho_{\mathrm{SiC}}$ may be completely filled up by silicon. The weight of silicon in this volume equals $P_{\mathrm{Si}}=\rho_{\mathrm{Si}}\left(1-3.33 \rho_{\mathrm{C}} / \rho_{\mathrm{SiC}}\right)$. Therefore, the maximum total density of $\mathrm{SiC} / \mathrm{Si}$ ceramics is $\rho_{\mathrm{s}}=$
$\rho_{\mathrm{Si}}\left(1-3.33 \rho_{\mathrm{C}} / \rho_{\mathrm{SiC}}\right)+3.33 \rho_{\mathrm{C}}$. Substitution of the values of densities of $\mathrm{Si} \rho_{\mathrm{Si}}=2.33 \mathrm{~g} / \mathrm{cm}^{3}$ and $\mathrm{SiC} \rho_{\mathrm{SiC}}=$ $3.2 \mathrm{~g} / \mathrm{cm}^{3}$ yields

$\rho_{s}=2.33+1.04 \rho_{\mathrm{C}}$.

The fit of the hardness results obtained using Eq. (4) and the $\rho_{s}$ value corresponding to ceramics of a particular sort of wood gives the value of $H_{v 0}$. The evaluation results are given in Table 1. 
Table 1. Mechanical parameters, experimental and estimated data.

\begin{tabular}{|l|c|c|c|c|c|}
\hline \multirow{2}{*}{ Material } & \multicolumn{2}{|c|}{ Geometrical density $\left(\mathrm{g} / \mathrm{cm}^{3}\right)$} & \multirow{2}{*}{$\rho_{\mathrm{s}}\left(\mathrm{g} / \mathrm{cm}^{3}\right)$} & $H_{v 0}(\mathrm{GPa})$ & $\begin{array}{c}\text { Maximum value of bending } \\
\text { strength, } B S(\mathrm{MPa})\end{array}$ \\
\cline { 2 - 3 } & Carbon matrices & Ceramics & & & 220 \\
\hline Alder & $0.50-0.55$ & $1.0-2.2$ & 2.89 & $6-15$ & 260 \\
\hline Beech & $0.45-0.55$ & $0.9-2.4$ & 2.89 & $10-20$ & 290 \\
\hline European hornbeam & $0.60-0.65$ & $1.2-2.6$ & 2.99 & $15-30$ & 260 \\
\hline Pear tree & $0.45-0.55$ & $0.9-2.4$ & 2.84 & $14-25$ & 260 \\
\hline Persian walnut & $0.50-0.60$ & $1.0-2.4$ & 2.94 & $7-13$ & 170 \\
\hline Pine & $0.20-0.30$ & $1.0-1.9$ & - & - & 260 \\
\hline Sapele wood & $0.55-0.60$ & $1.1-2.4$ & 2.94 & $6-12$ & 330 \\
\hline $\begin{array}{l}\text { Ceramics from bunches of } \\
\text { carbon fibers }\end{array}$ & - & $2.0-2.8$ & - & - & 400 \\
\hline Crystal 3C-SiC & - & 3.2 & - & - & \\
\hline
\end{tabular}
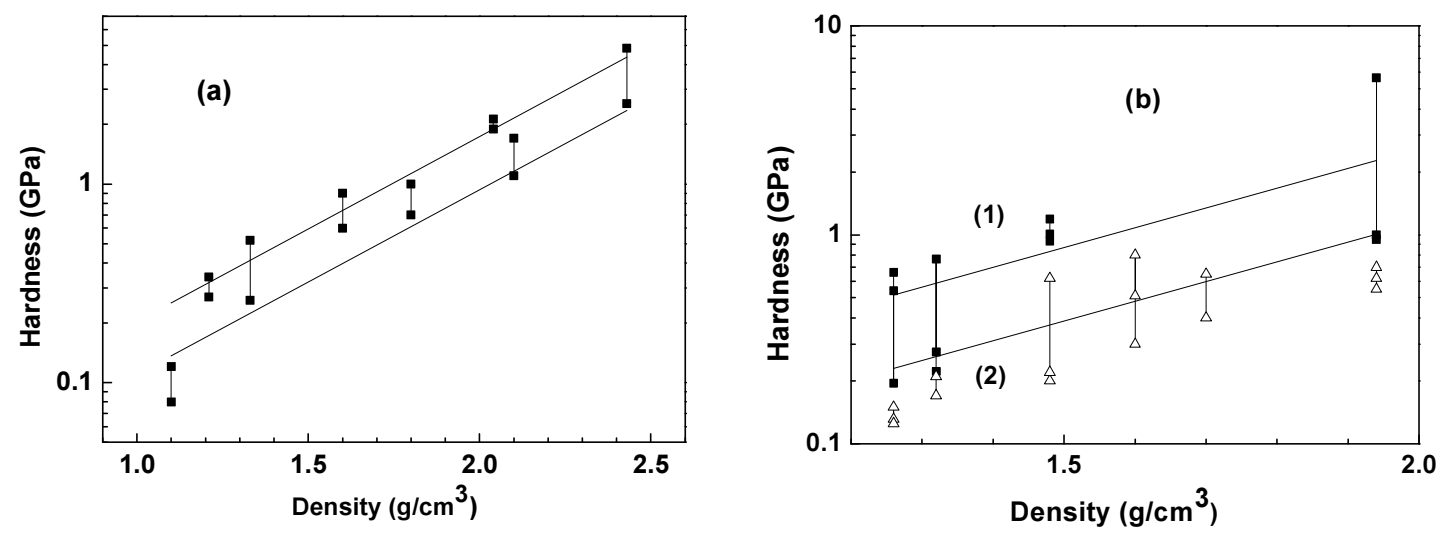

Fig. 3. Hardness results obtained as a function of geometrical density at ambient temperature. Ceramics made from: (a) Persian walnut and (b) alder. Upper lines correspond to orientations parallel to direction of wood growth, lower lines correspond to orientations normal to growth direction.

\subsection{Bending strength}

The bending strength $(B S)$ and Young's modulus, $E$, of bioSiCs were determined by using four-point bending tests at room temperature. Table 2 gives the mechanical properties of some specimens.

The measurement of bending and compressive strengths results in fracture of the specimens, so it will be useful to estimate such parameters from the geometrical density. It can be seen from Fig. 4 that, independently of the type of wood used for the ceramics, the experimental data on the bending strength fit the linear dependence well

$B S(\mathrm{MPa}) \approx 178 \rho-170$.

Table 2. Mechanical properties of bioSiC ceramics.

\begin{tabular}{|l|c|c|c|}
\hline \multicolumn{1}{|c|}{ Material } & $\begin{array}{c}\text { Density } \\
\left(\mathrm{g} / \mathrm{cm}^{3}\right)\end{array}$ & $\begin{array}{c}\text { Bending } \\
\text { strength, } \\
B S(\mathrm{MPa})\end{array}$ & $\begin{array}{c}\text { Young's } \\
\text { modulus, } E \\
(\mathrm{GPa})\end{array}$ \\
\hline $\begin{array}{l}\text { European } \\
\text { hornbeam }\end{array}$ & 2.43 & 180 & 292 \\
\hline $\begin{array}{l}\text { Persian walnut } \\
\text { (porosity A) }\end{array}$ & 1.20 & 32 & 93 \\
\hline $\begin{array}{l}\text { Persian walnut } \\
\text { (porosity B) }\end{array}$ & 1.65 & 40 & 102 \\
\hline
\end{tabular}

Similar linear dependences for the bending strength with the bioSiC geometrical density, elastic modulus and compressive strength were observed in studies [16-19]. Therefore, Eq. (6) can be considered useful for estimating the bending strength based on the known geometrical density.

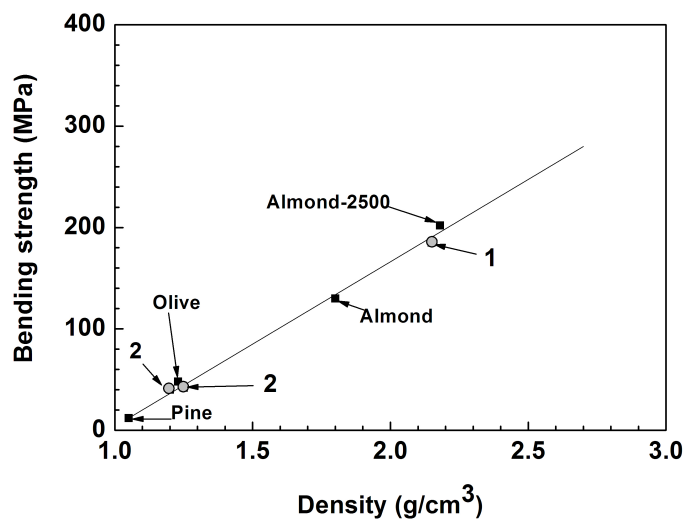

Fig. 4. Bending strength (BS) results measured as a function of geometrical density at ambient temperature. Ceramics made from European hornbeam (1) and pear tree (2). Open circles data from Ref. [16]. 

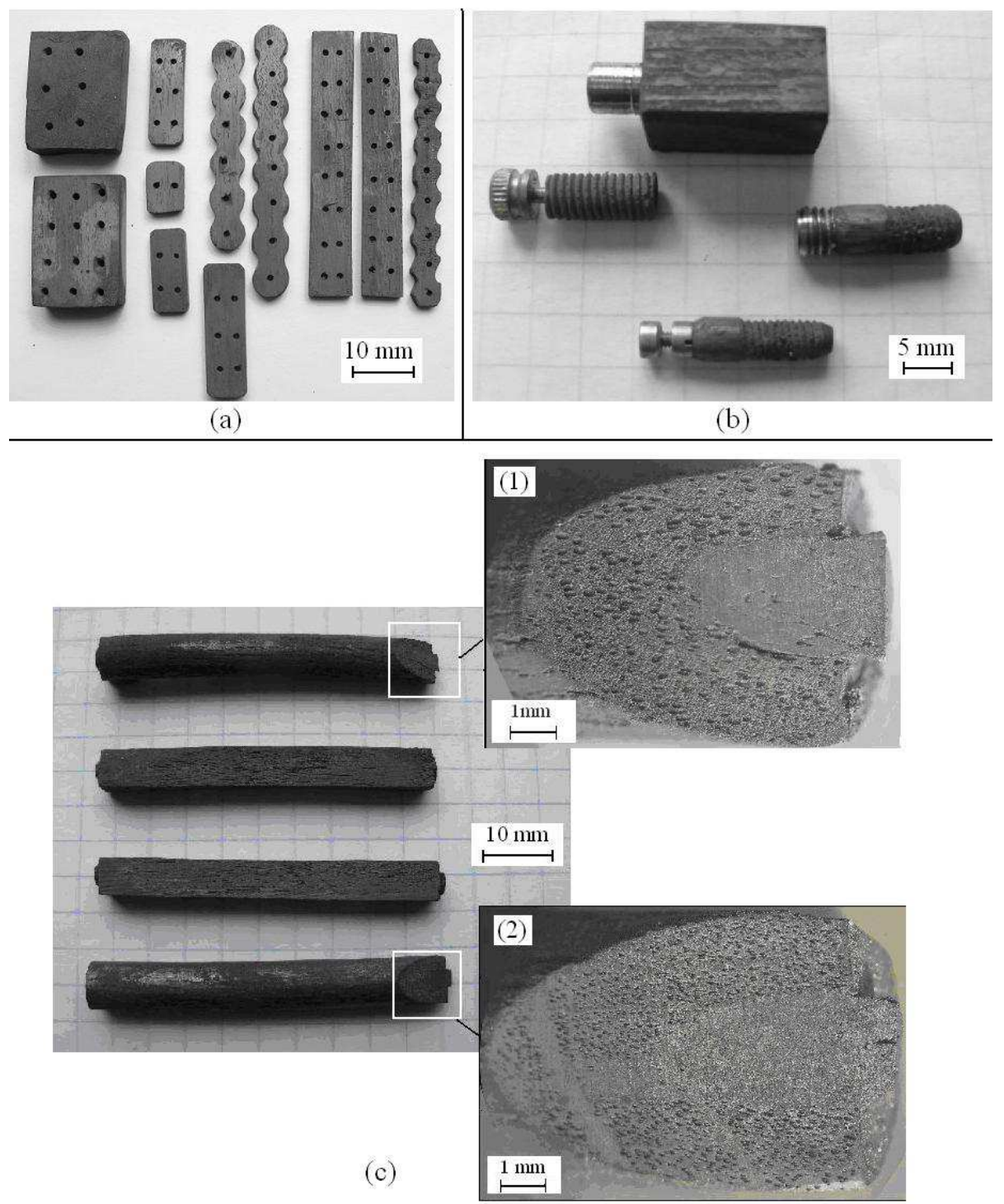

Fig. 5. Typical ceramic samples (a) and compound structure: (b) - SiC and Ti or stainless steel rods, (c) - SiC fabricated from bunches of carbon fibers and carbon matrices from wood: pear tree (1), European hornbeam (2).

The experimental data and structural parameters for ceramics made from different sorts of woods (Table 1) demonstrate that the mechanical properties of bioSiC ceramics depend on the properties of initial carbon matrices and amount of excess silicon. Increasing the amount of excess silicon leads to an increase in the density of the ceramics and, hence, to an improvement of the mechanical parameters.

\section{Designs of products and methods for reinforcement of ceramics}

It can be seen from Table 1 that the mechanical properties of the biomorphous $\mathrm{SiC}$ ceramics, especially the bending strength, fail to meet all the requirements imposed on the orthopedic implants. To improve these properties, we suggest using a compound structure. Inner metal ( $\mathrm{Ti}$, stainless steel) or ceramic rods can be used to reinforce the bioSiC ceramics [20]. In such products, the outer surface should be covered by the porous ceramics providing osteointegration, and the inner rods should be used to improve the mechanical properties. Fig. 5 shows examples of various ceramic products designed for applications in medicine.

Another way of improving mechanical properties may consist in impregnating items made from bioSiC ceramics with liquid $\mathrm{Ti}$. Impregnation with $\mathrm{Ti}$ was performed in a vacuum furnace at temperatures 1650 to $1700{ }^{\circ} \mathrm{C}$ in He atmosphere. Fig. 6 shows the dependence of the amount of $\mathrm{Ti}$ on the amount of $\mathrm{Si}$. These data

\section{(C) 2012, V. Lashkaryov Institute of Semiconductor Physics, National Academy of Sciences of Ukraine}



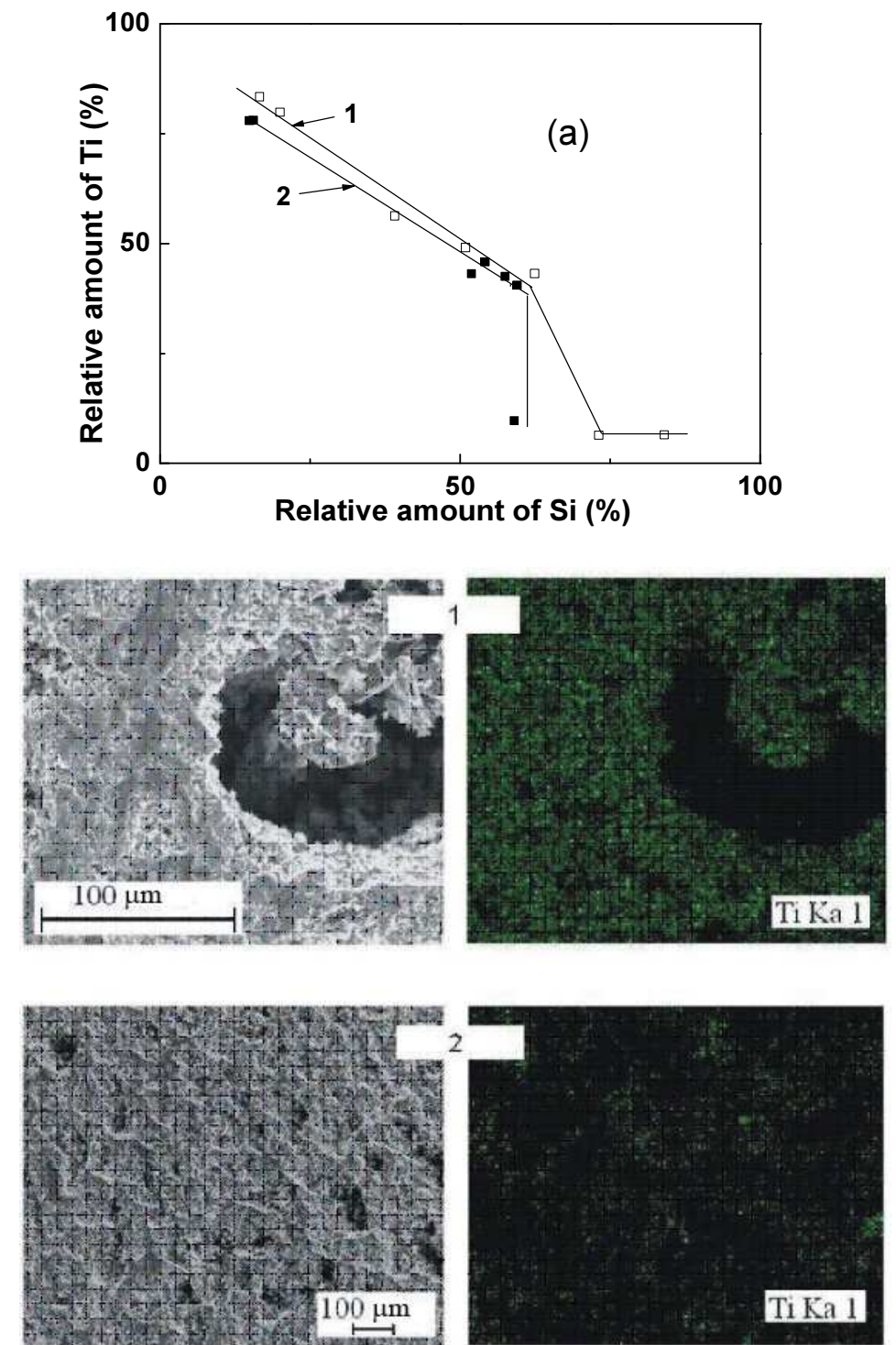

Fig. 6. Relative amount of $\mathrm{Ti}$ vs. amount of $\mathrm{Si}$ at different points on the surface of the ceramics (a). SEM images of the surface and distribution of characteristic radiation (b) of the ceramics.

were obtained by analyzing the element composition at the selected points on the specimen surfaces. It is known that the content of $\mathrm{Si}$ in stoichiometric $\mathrm{SiC}$ material is $70 \%$. Therefore, $\mathrm{Ti}$ only precipitates onto the porous points on the surface at $\mathrm{Si}<70 \%$, and no precipitation is observed at $\mathrm{Si}>70 \%$. Hence it follows that the $\mathrm{SiC} / \mathrm{C}$ bioceramic without the excess silicon should be used for impregnation with $\mathrm{Ti}$. Impregnation of the $\mathrm{SiC}$ ceramics with Ti may considerably improve their wear resistance. Therefore, such types of materials are promising for a broad range of applications.

\section{Conclusions}

Mechanical properties of biomorphous SiC ceramics, such as Vickers hardness and bending strength, were studied. It is shown that the properties of these materials strongly depend on the geometrical density of the ceramics. The dependence of the Vickers hardness of the ceramics made from hardwood can be well described using the Ryskevitch-type equation. The mechanical properties of five wood-based bioSiC materials are evaluated. Ceramic products for surgical applications have been designed. To improve wear resistance, the authors suggest impregnating porous ceramics with $\mathrm{Ti}$. The first results of in vitro and in vivo investigations show that biomorphic ceramics are promising materials for utilization in maxillofacial surgery and can replace traditionally applied $\mathrm{Ti}[21,22]$.

\section{Acknowledgements}

Team from ISP acknowledges financial support from Ukrainian State Program "Nanotechnology and nanomaterials". S. Pud would like to acknowledge the DAAD Foundation for financial support.

\section{(C) 2012, V. Lashkaryov Institute of Semiconductor Physics, National Academy of Sciences of Ukraine}




\section{References}

1. P. Gonzalez, J. Serra, S. Lista et al., New biomorphic $\mathrm{SiC}$ ceramics coated with bioactive glass for biomedical applications // Biomaterials, 24, p. 4827-4832 (2003).

2. J. Martinez Fernandez, A.R. de Arellano-Lopez, F.M. Varela-Feria, P. Gonzalez, J. Serra, S. Liste, et al. Material Biocompatible. Spanish Patent No. P200203052, 2002.

3. A. de Carlos, J.P. Borrajo, J. Serra, P. Gonzalez, B. Leon, Behaviour of MG-63 osteoblast-like cells on wood-based biomorphic $\mathrm{SiC}$ ceramics coated with bioactive glass // J. Mater. Sci: Mater. Med., 17, p. 523-529 (2006).

4. P. Gonzalez, J.P. Borrajo, J. Serra, S. Liste et al., Extensive studies on biomorphic $\mathrm{SiC}$ ceramics properties for medical applications // Key Eng. Materials, 254-256, p. 1029-1032 (2004).

5. M. Mahmoodi, L. Ghazanfar, Fundamentals of biomedical applications of biomorphic SiC. In: Properties and Applications of Silicon Carbide, Ed. R. Gerhardt. InTech: Open Access Publisher, 2011, p. 297-343.

6. An Introduction to Bioceramics. L.L. Hench, J. Wilson, editors. Singapore, World Scientific, 1993.

7. P. Greil, T. Lifka, A. Kaindl, Biomorphic cellular silicon carbide ceramics from wood: I. Processing and microstructure // J. Eur. Ceram. Soc. 18, p. 1961-1973 (1998).

8. X. Zhu, D. Jiang, S. Tan, Preparation of silicon carbide reticulated porous ceramics // Mater. Sci. and Eng. A, 323, p. 232-238 (2002).

9. F.M. Varela-Feria, J. Martinez-Fernandez, A.R. de Arellano-Lopez, M. Singh, Low density biomorphic silicon carbide: microstructure and mechanical properties // J. Eur. Ceram. Soc. 2002; 22: 2719-2725.

10. V.S. Kiselov, P.M. Lytvyn, V.O. Yukhymchuk, A.E. Belyaev, S.A. Vitusevich, Synthesis and properties of porous SiC ceramics // J. Appl. Phys. 107, 093510-1-6 (2010).

11. J. Gibson, M.F. Ashby, Cellular Solids: Structure and Properties. Cambridge University Press, 1999.
12. J. Martinez-Fernandez, F.M. Valera-Feria, M. Singh, High temperature compressive mechanical behavior of biomorphic silicon carbide ceramics // Scripta Mater. 43, p. 813-818 (2000).

13. P. Greil, E. Vogli, T. Fey et al. Effect of microstructure on the fracture behavior of biomorphous silicon carbide ceramics // J. Eur. Ceram. Soc. 22, p. 2697-2707 (2002).

14. R.W. Rice, Evaluation and extension of physical property-porosity models based on minimum solid area // J. Mater. Sci. 31, p. 102-118 (1996).

15. E. Ryshkewitch, Compression strength of porous sintered alumina and zirconia // J. Am. Ceram. Soc. 36, p. 65-68 (1953).

16. N.R. Calderon, M. Martinez-Escandell, J. Narciso, F. Rodriguez-Reinoso, The role of carbon biotemplate density in mechanical properties of biomorphic SiC // J. Eur. Ceram. Soc. 29, p. 465472 (2009).

17. M. Singh and J.A. Salem, Mechanical properties and microstructure of biomorphic silicon carbide ceramics fabricated from wood precursors // J. Eur. Ceram. Soc. 22, p. 2709-2717 (2002).

18. M. Presas, J.Y. Pastor, J. Llorca, A.R. ArellanoLopez, J. Martinez-Fernandez and R.E. Sepulveda, Mechanical behavior of biomorphic $\mathrm{Si} / \mathrm{SiC}$ porous composites // Scripta Mater. 53, p. 1175-1180 (2005).

19. F.M. Varela-Feria, J. Martinez-Fernandez, A.R. Arellano-Lopez, M. Singh, Low density biomorphic silicon carbide: Microstructure and mechanical properties // J. Eur. Ceram. Soc. 22, p. 2719-2725 (2002).

20. V.S. Kiselov, A.E. Belyaev, Method for fabrication of composite material based on silicon carbide for transplantation spongy bones and dentes implants. Ukrainian Patent No. 60572, 2011.

21. V.S. Kiselov, A.E. Belyaev, T.A. Aleksyeyeva et al., Comparison of implants based on titanium (Ti) and biomorphic SiC/Si ceramics biocapability // EMRS, Strasbourg Spring, 12 May 2011, P.XIV: Section P.2011.

22. O. Lazarenko, O. Petrenko, V. Malanchuk, E. Solodukha, K. Ploticyna, V. Litvinov, Determination of biomorphic ceramics based on silicized carbon biocompability // EMRS, Strasbourg Spring, 12 May 2011, P.XIV: Section P.2011. 